This is an Accepted Manuscript of an article published by Thieme in Hormone and Metabolic Research on 2018, available online at http://www.thieme-

connect.com/products/ejournals/abstract/10.1055/a-0631-2468.

DOI:10.1055/a-0631-2468

Copyright (C) 2018, Rights Managed by Georg Thieme Verlag KG Stuttgart • New York 


\section{Diabetes mellitus and autoimmune hepatitis: Demographical and clinical description of a relatively rare phenotype.}

Running title: Diabetes and autoimmune hepatitis

Authors:

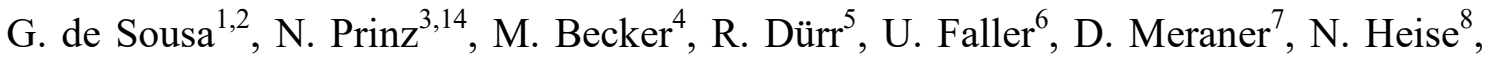
I. Engelmann ${ }^{9}$, H. Bruckmayer ${ }^{10}$, D. Wiemann ${ }^{11}$, M. Fritsch ${ }^{12}$, B. Stratmann ${ }^{13}$, and R. W. Holl ${ }^{3,14}$

${ }^{1}$ Children's Hospital Dortmund, Germany

${ }^{2}$ Department of Pediatrics, University of Witten/Herdecke, Germany

${ }^{3}$ Institute of Epidemiology and Medical Biometry, Central Institute for Biomedical Technology, University of Ulm, Germany

${ }^{4}$ Children's Hospital, Helios Dr. Horst Schmidt Kliniken Wiesbaden, Germany

${ }^{5}$ Children's Hospital Rems-Murr, Germany

${ }^{6}$ Children's Hospital, Oberschwabenklinik, Ravensburg, Germany

${ }^{7}$ Department of Pediatrics and Adolescent Medicine, University Innsbruck, Austria

${ }^{8}$ Department of Internal Medicine, Helfenstein Klinik, Geislingen/Steige, Germany

${ }^{9}$ Department of Internal Medicine, Medius Kliniken, Nürtingen, Germany

${ }^{10}$ Department of Internal Medicine, Hospital Ruhpolding, Germany

${ }^{11}$ Department of Pediatrics, University of Magdeburg, Germany

${ }^{12}$ Department of Pediatrics and Adolescent Medicine, Medical University Vienna, Austria

${ }^{13}$ Diabeteszentrum, Herz- und Diabeteszentrum NRW, Ruhr-Universität Bochum, Bad Oeynhausen, Germany

${ }^{14}$ German Center for Diabetes Research (DZD), Munich-Neuherberg

Corresponding author:

Priv.-Doz. Dr. med. Gideon John de Sousa, M.A.

Children's Hospital Dortmund, Beurhausstr. 40

44137 Dortmund Germany

Tel.: ++49-231-953-21707 
Fax: ++ 49-231-953-21008

E-Mail: gideon.desousa@klinikumdo.de

\section{Abstract}

Aims: We studied demographic, metabolic, and clinical characteristics of patients with diabetes and autoimmune hepatitis (AIH) from the German/Austrian DPV registry.

Methods: 139 patients with diabetes and AIH were analyzed and compared to 437728 patients with diabetes without AIH.

Results: The prevalence of AIH in patients with T1DM (44.8/100,000) seems higher than in the general population, the prevalence of $\mathrm{AIH}$ in patients with $\mathrm{T} 2 \mathrm{DM}$ $(23.6 / 100,000)$ does not seem to be increased. Patients with T2DM and AIH had a shorter duration of diabetes $(p=0.007)$ and a higher proportion of females $(p<0.001)$ compared to T2DM without $\mathrm{AIH}$. Patients with diabetes (T1DM or T2DM) and AIH required higher insulin doses $(\mathrm{p}<0.001$ resp. $\mathrm{p}=0.03)$ and showed increased liver enzymes (aspartate transaminase, alanine transaminase, gamma-glutamyltransferase) compared to diabetes patients without (all $\mathrm{p}<0.001$ ). We detected a lower percentage of patients treated with oral antidiabetic drugs $(\mathrm{p}=0.01)$ and a higher percentage of patients treated by insulin in patients with $\mathrm{T} 2 \mathrm{DM}$ and $\mathrm{AIH}(\mathrm{p}<0.001)$ compared to patients with T2DM alone. We observed a higher incidence of autoimmune thyroid disease (AIT) in patients with diabetes $(\mathrm{T} 1 \mathrm{DM}$ or $\mathrm{T} 2 \mathrm{DM})$ and $\mathrm{AIH}(\mathrm{p}<0.001)$ compared to diabetes patients without AIH.

Conclusions: AIH seems more frequent in patients with T1DM. Patients with diabetes and $\mathrm{AIH}$ require intensification of antidiabetic therapy and seem to have a higher prevalence of AIT. 
Key words: type 1 diabetes - type 2 diabetes - autoimmune thyroid disease - clinical outcome - diabetes treatment

\section{Introduction}

The pathogenesis of type 1 diabetes mellitus (T1DM) is characterized by autoimmune destruction of beta cells in the pancreas [1]. Being an autoimmune disorder, T1DM is associated with other immune-mediated diseases, such as autoimmune thyroid disease (AIT) [2], celiac disease [3, 4], and Addison's disease [5], suggesting a common genetic susceptibility [6].

Up to now, only a few case reports have been published on patients with T1DM and autoimmune hepatitis $(\mathrm{AIH})[6,7,8]$. Hovinga et al. described the case of a 12 -year-old girl with T1DM who developed AIH. Interestingly, human leucocyte antigen typing of the girl showed DRB1*03 heterozygosity, which has been associated with both AIH and T1DM suggesting that perhaps similar pathogenic pathways are involved in different autoimmune conditions, including T1DM and AIH [6]. This assumption is supported by the fact that a relationship between celiac disease and AIH has been reported $[9,10]$. The pathomechanistic relationship between AIH and other autoimmune processes, however, has only been poorly investigated so far [8].

On the other hand, also patients with type 2 diabetes mellitus (T2DM) have been found to express autoimmune characteristics, including the presence of autoantibodies against pancreatic beta cells and self-reactive T-cells [11]. Accordingly, associations have been observed between psoriasis and T2DM, and rheumatoid arthritis and T2DM [12, 13]. 
Analysing the relationships between T2DM and autoimmune diseases, Hemminki et al. found 15,103 patients with T2DM among 757,368 patients with autoimmune diseases. An overall SIR (Standardized incidence ratio) of 1.66 for T2DM was calculated. T2DM risks were clearly increased after 27 of 32 autoimmune diseases; the highest SIR were calculated for chorea minor (8.00), autoimmune hepatitis (5.75), and Addison's disease (2.63) [11]. To the best of our knowledge, studies investigating a possible link between T2DM and AIH, however, have not been published yet.

As AIH is treated with corticosteroids $[14,15,16]$, the question arises whether glycemic control of patients with diabetes and $\mathrm{AIH}$ deteriorates and in turn results in higher HbA1c-values. It could further be possible that patients with T2DM and AIH undergoing treatment with corticosteroids require an intensification of their antihyperglycemic treatment with a shift from oral antidiabetic drugs towards insulin treatment. Finally, it would be interesting to know whether the frequency of other immune-mediated diseases, such as AIT and celiac disease, is increased in patients with diabetes and comorbid $\mathrm{AIH}$.

Studies describing a larger group of patients with diabetes (T1DM or T2DM) and comorbid AIH, however, have not been published so far. We therefore aimed to study demographic, metabolic, and clinical characteristics in a sufficiently large cohort of patients with diabetes and $\mathrm{AIH}$ and compare them to patients with diabetes without AIH. 


\section{Research Design and Methods}

\subsection{Data Source}

The standardized, multicenter, prospective, computer-based diabetes data acquisition system DPV (www.d-p-v.eu) was used in this study. The DPV initiative currently comprises 451 diabetes care centers from Germany, Austria, Switzerland, and Luxembourg using the DPV software for standardized documentation of diabetes diagnosis and patient care. The electronic health record contains demographic data, type and onset of diabetes, data on metabolic control and treatment regimen, and information on comorbidities. The locally documented information is transmitted twice a year anonymously to Ulm, Germany, for central analyses and quality assurance $[17,18]$. If necessary, centers are requested to correct inconsistent data. All plausible data are then aggregated into a cumulative database. The DPV initiative was approved by the ethics committee of the University of Ulm and the data documentation by the local review boards. Until September 2016, demographic and clinical data of 452,493 patients with any type of diabetes were recorded in the database.

\subsection{Subjects}

For the present study, patients with T1DM, T2DM or other specific types of diabetes (type 3 diabetes mellitus (T3DM)) were considered. The database was searched for the 
additional lifetime diagnosis of AIH by ICD-10 code (k75.4) and specific German search terms considering different spellings (e.g. "autoimmun hepatitis", "autoimmune hepatitis", "autoimunhepatitis“, "autoimunehepatitis"). The final study population comprised 437,728 pediatric and adult patients with diabetes without AIH and 139 patients with AIH from 411 German, 37 Austrian, 2 Swiss, and 1 Luxembourgian centers. For each patient included, data from the last documented visit were studied.

\subsection{Variables analyzed}

- We analyzed demographic data (age, sex, body-mass-index (BMI), duration of diabetes), glycemic control (HbAlc,), insulin dose in units/ $\mathrm{kg}$ as well as treatment regimen. In T1DM, treatment regimen was classified as conventional insulin therapy (13 insulin injections/day), intensive insulin treatment (4-8 insulin injections/day) insulin pump therapy ( 9 insulin injections/day), and additional administration of oral antidiabetic drugs (OAD). In T2DM, anti-hyperglycemic treatment was categorized by insulin only, insulin and OAD, OAD only, and lifestyle modification only. Additionally, we analyzed liver enzymes (aspartate transaminase, alanine transaminase, gammaglutamyltransferase) and in T1DM diabetes autoantibodies (islet cell antibodies, insulin autoantibodies, glutamic acid decarboxylase, protein tyrosine phosphatase). Finally, our analysis also evaluated the frequency of documented celiac disease (diagnosis confirmed by small-bowel biopsy) or AIT.

To adjust for differences between laboratory methods, the multiple of the mean method was applied to mathematically standardize $\mathrm{HbAlc}$ measurements to the Diabetes Control and Complications Trial (DCCT) reference range (20.7-42.6 mmol/mol) [19]. 


\subsection{Statistics}

Data analysis was performed using SAS 9.4 (SAS Institute, Cary, NC). Results were presented as median with quartiles or proportion. We compared patients with either T1DM or T2DM and AIH to patients with T1DM or T2DM without AIH. Wilcoxontest was used for continuous variables and $\chi^{2}$-test for binary variables. P-values were corrected for multiple comparisons using FDR algorithm (false discovery rate). To account for potential confounding effects such as age, sex and duration of diabetes, multivariable regression models were created to compare diabetes-related outcome variables between groups. Linear regression was used for continuous variables, logistic regression for binary data. Between-within method was applied to calculate denominator degrees of freedom. Restricted maximum likelihood was used as estimation technique in linear regression and maximum likelihood for logistic regression. Results are given as adjusted means with standard error of the mean (SEM). Two-sided p-values $<0.05$ were defined as statistically significant. 


\section{Results}

Table 1 summarizes the frequency of AIH by type of diabetes in the entire cohort, with significant difference among groups $(\mathrm{p}<0.001)$. The majority of patients with T3DM and $\mathrm{AIH}$ had uncommon forms of immune-mediated diabetes and diabetes caused by drugs

i.e. $\quad$ corticosteroids

(table

2).

Information on the type of AIH was available only in 38/139 patients (29 patients type 1 $\mathrm{AIH}, 9$ patients type $2 \mathrm{AIH}$ ) after specific request at the participating centers. Analyses stratified by type of AIH were therefore not possible.

Comparisons of demographics (age, sex, duration of diabetes) are shown in tables 3 and 4. The patients with T2DM and AIH had a significantly shorter duration of diabetes than the patients with T2DM without AIH $(\mathrm{p}=0.007)$. Furthermore, the group of patients with T2DM and AIH had a higher percentage of female patients when compared to the group of patients with T2DM without AIH $(\mathrm{p}<0.001)$. T1DM patients with or without AIH did not differ with regard to age, sex and diabetes duration.

Demographically adjusted comparisons of metabolic and clinical variables are summarized in tables 3 and 4. Patients with diabetes (T1DM or T2DM) and AIH required significantly higher insulin doses $(p<0.001$ resp. $p=0.03)$ and showed higher levels of liver enzymes than patients with diabetes without AIH (both $\mathrm{p}<0.001$ ). In 
comparison to patients with T2DM without $\mathrm{AIH}$, we detected a lower percentage of patients treated by oral antidiabetic drugs $(\mathrm{p}=0.01)$ and a higher percentage of patients treated by insulin only $(\mathrm{p}<0.001)$ in patients with T2DM and AIH. Finally, we observed a higher frequency of AIT in patients with diabetes (T1DM or T2DM) and AIH when compared to patients with T1DM or T2DM without AIH (p-values both $<0.001$ ). In T1DM with or without $\mathrm{AIH}$, metabolic control and type of diabetes treatment regimen did not differ significantly. Nutritional status assessed by BMI or BMI-SDS were comparable between diabetes patients (T1DM or T2DM) with or without AIH.

Group comparisons of patients with T3DM were not possible due to the limited number of subjects with AIH in this subgroup $(n=15)$. 


\section{Discussion}

To the best of our knowledge, this is the first study comparing demographic, metabolic, and clinical characteristics between patients with diabetes and $\mathrm{AIH}$ and patients with diabetes without $\mathrm{AIH}$.

Epidemiological data on $\mathrm{AIH}$ are rather scarce and heterogeneous, as the prevalence of AIH differs in various geographic regions, between different age groups, and between Type 1 AIH and Type 2 AIH [20-23]. As pointed out by Kim et al., prevalence estimates of $\mathrm{AIH}$ therefore range widely from 4 to 42.9 cases per 100,000 persons [23]. Therefore, conclusions from comparisons between data have to be drawn very carefully. Only two studies have assessed the population-based prevalence of AIH in Europe detecting a prevalence of $16.9 / 100,000$ and $24.5 / 100,000$ respectively $[21,24]$. The prevalence of AIH in our group of patients with T1DM was 44.8/100,000 and 23.6/100,000 in the group of patients with T2DM. It therefore seems that the prevalence of AIH is increased in patients with T1DM pointing towards a possible autoimmunological link between these two diseases. The prevalence of AIH in patients with T2DM seems to be similar to the prevalence in the general population possibly pointing towards the fact that these two diseases are not associated. Up to now, however, a possible relationship between T1DM and AIH has been poorly investigated, mainly restricted to immunological aspects $[1,25-28]$. 
One focus of our analysis was to compare the frequency of AIT and celiac disease in these two groups, as T1DM and AIH are both associated with AIT and celiac disease [2-4, 25, 27, 29-31]. In our analysis, patients with diabetes (T1DM and T2DM) and AIH did not differ from patients without $\mathrm{AIH}$ with respect to the rate of celiac disease. By contrast, $\mathrm{p}$ atients with T1DM and $\mathrm{AIH}$ or with T2DM and AIH demonstrated a higher frequency of AIT compared to patients with diabetes without AIH. As classified by Neufeld et al., patients with AIT, insulin-requiring diabetes, and at least one other autoimmune disease fulfill the definition of Autoimmune Polyglandular Syndrome Type III A (APS III A) in the absence of Addison's disease [32], so that our group of patients with AIT, T1DM, and AIH can be diagnosed to have APS III A. Addison's disease was not diagnosed in any of these patients. Autoimmune Polyglandular Syndrome is considered to be a rare form of autoimmune disorder [33, 34]. The exact prevalence of APS III is unknown as epidemiological data are limited [35]. In a study with 461 children with T1DM, however, Ben-Skowronek et al. detected APS III in 14.5\% of their patients [36]. Reports on patients with AIH as part of APS III are limited to two casereports in adults $[10,37]$.

Interestingly, patients with $\mathrm{T} 2 \mathrm{DM}$ and $\mathrm{AIH}$ also showed a higher prevalence of AIT as compared to patients with T2DM without AIH. Studies or reports on patients with T2DM, AIH, and AIT are lacking so far. However, patients with T2DM have also been found to express autoimmune characteristics, including the presence of autoantibodies against pancreatic beta cells and self-reactive T-cells [11]. Furthermore, the association between T2DM, AIH, and AIT is also explained by the established association between AIH and AIT [29] which does not exclude patients with T2DM. 
When comparing glycemic control (assessed by HbA1c), we did not find differences between patients with diabetes (T1DM or T2DM) with or without AIH. In order to achieve comparable HbA1c-values, however, patients with diabetes (T1DM or T2DM) with AIH required higher insulin doses. The necessity to intensify antidiabetic therapy in patients with diabetes and $\mathrm{AIH}$ is further illustrated by the fact that the proportion of patients treated with insulin only was higher in the group of patients with T2DM and $\mathrm{AIH}$, and accordingly the rate of patients being treated with oral antidiabetic drugs only was lower in this group.

The necessity to intensify antidiabetic treatment in patients with diabetes and AIH can be explained by the use of corticosteroids in the management of AIH [14-16]. Corticosteroids are known to cause postprandial hyperglycemia. Part of the mechanism of hyperglycemia involves peripheral insulin resistance, which leads to an increase in insulin requirement $[38,39]$. Additionally, corticosteroids increase hepatic glucose production [40]. Diabetes caused by treatment with corticosteroids is classified as T3DM. The prevalence of T3DM in patients with AIH being treated with corticosteroids is unknown [41]. In our analysis of 139 patients with AIH and diabetes, we found 7 patients with T3DM as a consequence of steroid treatment. Matsumoto et al. analyzed 118 adult patients with AIH and found diabetes in 29 (24.5\%) patients, one of these having T1DM. $21(72.4 \%)$ of the patients with diabetes received corticosteroids [41]. Otherwise, data on the occurrence of diabetes in patients with AIH undergoing treatment with corticosteroids are lacking. Furthermore, insulin resistance and consecutive hyperglycemia can be a consequence of inflammation in patients with $\mathrm{AIH}$. In inflammatory disorders, pro-inflammatory cytokines can cause insulin resistance in adipose tissue, skeletal muscle, and liver by inhibiting insulin signal transduction [42, 
43]. Finally, hyperglycemia and diabetes can be a complication of chronic liver diseases $[44,45]$.

The strength of this study is that we were able to examine a sufficient number of patients with diabetes and AIH. To our best knowledge, this is the first report on demographic, metabolic, and clinical characteristics of patients with diabetes and AIH. A potential limitation of our study is the fact that we did not have sufficient data concerning the type of $\mathrm{AIH}$, even after request at the participating centers. Further analyses separated by type of AIH would be of great interest but were not possible. Furthermore, our study is based on data and diagnoses from a registry. Detailed data on the diagnostic criteria concerning the diagnosis of $\mathrm{AIH}$, such as histology, severity, or fibrosis, are therefore not available to us. Similarly, comprehensive data on the treatment of AIH (e.g. type of medication, dosages, duration of treatment) and clinical course (e.g. remission, relapses) are not available in the DPV registry. However, we were able to elicit that $53 \%$ of the patients with diabetes and AIH were treated with corticosteroids. Of these patients, $14 \%$ of casesused corticosteroids already at the onset of diabetes.

In conclusion, the results of our analyses show that AIH seems to be more frequent in patients with T1DM. Furthermore, patients with diabetes (T1DM or T2DM) and AIH require an intensification of their antidiabetic therapy. Finally, patients with diabetes (T1DM or T2DM) and AIH seem to have a higher prevalence of AIT. Patients with T1DM, AIH, and AIT represent APS III A, a rare autoimmune disorder which has been less studied so far. 
Duality of Interest: No potential conflicts of interest relevant to this article were reported. The authors have no competing interests to declare.

Author Contributions: GdS created tables and wrote and edited the manuscript. NP edited the manuscript. MB, RD, UF, DM, NH, IE, HB, DW, MF, and BS researched data and reviewed the manuscript. RH conceptualized the study and reviewed the manuscript. $\mathrm{RH}$ is the guarantor of this work and, as such, had full access to all the data in the study and takes responsibility for the integrity of the data and the accuracy of the data. All authors have approved the final article.

Financial support: The Federal Ministry of Education and Research within the German Center for Diabetes Research (DZD) financially supported the study. Further funding has been received from the Innovative Medicines Initiative 2 Joint Undertaking under grant agreement No 115797 (INNODIA) supported by the European Union's Horizon 2020 research and innovation program and "EFPIA", 'JDRF" and "The Leona M. and Harry B. Helmsley Charitable Trust". The German Diabetes Association (DDG), the European Foundation for the Study of Diabetes (EFSD) and the German Robert Koch Institute (RKI) provided additional financial support. Sponsors were not involved in data acquisition or analysis. 


\section{References}

[1] Al-Hussaini AA, Alzahrani MD, Alenizi AS, Suliman NM, Khan MA, Alharbi SA, Chentoufi AA. Autoimmune hepatitis related autoantibodies in children with type 1 diabetes. Diabetol Metab Syndr 2014; 6: 38

[2] Umpierrez GE, Latif KA, Murphy MB, Lambeth HC, Stentz F, Bush A, Kitabchi AE. Thyroid dysfunction in patients with type 1 diabetes: a longitudinal study. Diabetes Care 2003; 26: 1181-1185

[3] Gillett PM, Gillett HR, Israel DM, Metzger DL, Stewart L, Chanoine JP, Freeman HJ. High prevalence of celiac disease in patients with type 1 diabetes detected by antibodies to endomysium and tissue transglutaminase. Can J Gastroenterol 2001; 15: 297-301

[4] Bao F, Yu L, Babu S, Wang T, Hoffenberg EJ, Rewers M, Eisenbarth GS. One third of HLA DQ2 homozygous patients with type 1 diabetes express celiac disease associated transglutaminase autoantibodies. J Autoimmun 1999; 13: 143-148

[5] Yu L, Brewer KW, Gates S, Wang T, Babu S, Gottlieb PA, Freed BM, Noble J, Erlich HA, Eisenbarth GS. DRB1*04 and DQ alleles: expression of 21-hydroxylase autoantibodies and risk of progression to Addison's disease. J Clin Endocrinol Metab 1999; 84: 328-335

[6] Hovinga IC, Stam ED, Mearin ML, Mul D. A girl with type 1 diabetes and a yellowish appearance. BMJ Case Rep 2010; 26: 1-4 
[7] De Block CE, De Leeuw IH, Pelckmans PA, Michielsen PP, Bogers JJ, Van Marck

EA, Van Gaal LF. Autoimmune hepatitis, autoimmune gastritis, and gastric carcinoid in a type 1 diabetic patient: a case report. J Diabetes Complications 2000; 14: 116-20

[8] Sotelo-Cruz N, López-Cervantes G, Campbell-Araujo OA. Immunological disorders: (Type 1 Diabetes, Idiopathic Thrombocytopenic Purpura and Hashimoto Encephalopathy), Associated with Autoimmune Hepatitis. Immunome Res 2015; 11: 2

[9] Nastasio S, Sciveres M, Riva S, Filippeschi IP, Vajro P, Maggiore G. Celiac disease-associated autoimmune hepatitis in childhood: long-term response to treatment. J Pediatr Gastroenterol Nutr 2013; 56: 671-4

[10] Dieli-Crimi R, Núñez C, Estrada L, López-Palacios N. An autoimmune polyglandular syndrome complicated with celiac disease and autoimmune hepatitis. Ann Hepatol_2016; 15: 588-91

[11] Hemminki K, Liu X, Försti A, Sundquist J, Sundquist K, Ji J. Subsequent Type 2 Diabetes in Patients with Autoimmune Disease. Sci Rep 2015; 5: 13871

[12] Solomon DH, Love TJ, Canning C, Schneeweiss S. Risk of diabetes among patients with rheumatoid arthritis, psoriatic arthritis and psoriasis. Ann Rheum Dis 2010; 69: 2114-7 
[13] Dubreuil M, Rho YH, Man A, Zhu Y, Zhang Y, Love TJ, Ogdie A, Gelfand JM, Choi HK. Diabetes incidence in psoriatic arthritis, psoriasis and rheumatoid arthritis: a UK population-based cohort study. Rheumatology 2014; 53: 346-52

[14] Soloway RD, Summerskill WH, Baggenstoss AH, Geall MG, Gitnićk GL, Elveback IR, Schoenfield LJ. Clinical, biochemical, and histological remission of severe chronic active liver disease: a controlled study of treatments and early prognosis. Gastroenterology 1972; 63: 820-833

[15] Cook GC, Mulligan R, Sherlock S. Controlled prospective trial of corticosteroid therapy in active chronic hepatitis. Q J Med 1971; 40: 159-185

[16] Yoneyama K, Honda E, Kogo M, Kiuchi Y, Shibata M, Mitamura K, Inawari M. Efficacy and safety of prednisolone in patients with autoimmune hepatitis. Adv Ther 2006; 23: 74-91

[17] Warncke K, Fröhlich-Reiterer EE, Thon A, Hofer SE, Wiemann D, Holl RW; DPV Initiative of the German Working Group for Pediatric Diabetology; German BMBF Competence Network for DiabetesMellitus. Polyendocrinopathy in children, adolescents, and young adults with type 1 diabetes: a multicenter analysis of 28,671 patients from the German/Austrian DPV-Wiss database. Diabetes Care 2010; 33: 20102012 
[18] Bechtold S, Blaschek A, Raile K, Dost A, Freiberg C, Askenas M, FröhlichReiterer E, Molz E, Holl RW. Higher Relative Risk for Multiple Sclerosis in a Pediatric and Adolescent Diabetic Population: Analysis From DPV Database. Diabetes Care 2014; 37: 96-101

[19] Rosenbauer J, Dost A, Karges B, Hungele A, Stahl A, Bächle C, Gerstl EM, Kastendieck C, Hofer SE, Holl RW; DPV Initiative and the German BMBF Competence Network Diabetes Mellitus. Improved metabolic control in children and adolescents with type 1 diabetes: a trend analysis using prospective multicenter data from Germany and Austria. Diabetes Care 2012; 35: 80-86

[20] Francque S, Vonghia L, Ramon A, Michielsen P. Epidemiology and treatment of autoimmune hepatitis. Hepat Med 2012; 4: 1-10

[21] Boberg KM. Prevalence and epidemiology of autoimmune hepatitis. Clin Liver Dis 2002; 6: 635-47

[22] Jiménez-Rivera C, Ling SC, Ahmed N, Yap J, Aglipay M, Barrowman N, Graitson S, Critch J, Rashid M, Ng VL, Roberts EA, Brill H, Dowhaniuk JK, Bruce G, Bax K, Deneau M, Guttman OR, Schreiber RA, Martin S, Alvarez F. Incidence and Characteristics of Autoimmune Hepatitis. Pediatrics 2015; 136: e1237-48

[23] Kim BH, Choi HY, Ki M, Kim KA, Jang ES, Jeong SH. Population-based prevalence, incidence, and disease burden of autoimmune hepatitis in South Korea. PLoS One 2017; 12: e0182391 
[24] Ngu JH, Bechly K, Chapman BA, Burt MJ, Barclay ML, Gearry RB, Stedman CA. Population-based epidemiology study of autoimmune hepatitis: a disease of older women? J Gastroenterol Hepatol 2010; 25: 1681-6

[25] Teufel A, Weinmann A, Kahaly GJ, Centner C, Piendl A, Wörns M, Lohse AW, Galle PR, Kanzler S. Concurrent autoimmune diseases in patients with autoimmune hepatitis. J Clin Gastroenterol_2010; 44: 208-13

[26] da Silva ME, Porta G, Goldberg AC, Bittencourt PL, Fukui RT, Correia MR, Miura IK, Pugliese RS, Baggio VL, Cançado EL, Kalil J, Santos RF, Rochal DM, Wajchenberg BL, Ursich MJ, Rosenbloom AL. Diabetes mellitus-related autoantibodies in childhood autoimmune hepatitis. J Pediatr Endocrinol Metab_2002; 15: 831-40

[27] Gregorio GV, Portmann B, Reid F, Donaldson PT, Doherty DG, McCartney M, Mowat AP, Vergani D, Mieli-Vergani G. Autoimmune hepatitis in childhood: a 20-year experience. Hepatology 1997; 25: 541-7

[28] Heras P, Mantzioros M, Mendrinos D, Heras V, Hatzopoulos A, Xourafas V, Kritikos K, Karagiannis S. Autoantibodies in type 1 diabetes. Diabetes Res Clin Pract 2010; 90: e40-2

[29] Cindoruk M, Yetkin I, Karakan T, Kandilci U. The prevalence of autoimmune hepatitis in Hashimoto's thyroiditis in a Turkish population. Acta Gastroenterol Belg $2002 ; 65: 143-5$ 
[30] Caprai S, Vajro P, Ventura A, Sciveres M, Maggiore G; SIGENP Study Group for Autoimmune Liver Disorders in Celiac Disease. Autoimmune liver disease associated with celiac disease in childhood: a multicenter study. Clin Gastroenterol Hepatol 2008; 6: $803-6$

[31] Peng M, Li Y, Zhang M, Jiang Y, Xu Y, Tian Y, Peng F, Gong G. Clinical features in different age groups of patients with autoimmune hepatitis. Exp Ther Med 2014; 7: 145

[32] Neufeld M, Maclaren N, Blizzard R. Autoimmune polyglandular syndromes. Pediatr Ann 1980; 9: 154-62

[33] Kahaly GJ. Polyglandular autoimmune syndromes. Eur J Endocrinol 2009; 161: $11-20$

[34] Shimomura H, Nakase Y, Furuta H, Nishi M, Nakao T, Hanabusa T, Sasaki H, Okamoto K, Furukawa F, Nanjo K. A rare case of autoimmune polyglandular syndrome type 3. Diabetes Res Clin Pract 2003; 61: 103-8

[35] Norasyikin AW, Rozita M, Mohd Johan MJ, Suehazlyn Z. Autoimmune polyglandular syndrome presenting with jaundice and thrombocytopenia. Med Princ Pract 2014; $23: 387-9$ 
[36] Ben-Skowronek I, Michalczyk A, Piekarski R, Wysocka-Łukasik B, Banecka B. Type III Polyglandular Autoimmune Syndromes in children with type 1 diabetes mellitus. Ann Agric Environ Med 2013; 20: 140-6

[37] Oki K, Yamane K, Koide J, Mandai K, Nakanishi S, Fujikawa R, Kohno N. A case of polyglandular autoimmune syndrome type III complicated with autoimmune hepatitis. Endocr J 2006; 53: 705-9

[38] Brady V, Thosani S, Zhou S, Bassett R, Busaidy NL, Lavis V. Safe and effective dosing of basal-bolus insulin in patients receiving high-dose steroids for hypercyclophosphamide, doxorubicin, vincristine, and dexamethasone chemotherapy. Diabetes Technol Ther 2014; 16: 874-9

[39] Clore JN, Thurby-Hay L. Glucocorticoid-induced hyperglycemia. Endocr Pract 2009; 15: 469-474

[40] van Raalte DH, Ouwens DM, Diamant M. Novel insights into glucocorticoidmediated diabetogenic effects: towards expansion of therapeutic options? Eur J Clin Invest 2009; 39: 81-93

[41] Matsumoto N, Ogawa M, Matsuoka S, Moriyama M. Prevalence and Risk Factors of Diabetes Mellitus in Patients with Autoimmune Hepatitis. Intern Med 2016; 55: 87985 
[42] de Luca C, Olefsky JM. Inflammation and insulin resistance. FEBS Lett 2008; 582: $97-105$

[43] Shoelson SE, Lee J, Goldfine AB. Inflammation and insulin resistance. J Clin Invest 2006; 116: 1793-801

[44] Kingston ME, Ali MA, Atiyeh M, Donnelly RJ. Diabetes mellitus in chronic active hepatitis and cirrhosis. Gastroenterology 1984; 87: 688-694

[45] Stepanova M, Rafiq N, Younossi ZM. Components of metabolic syndrome are independent predictors of mortality in patients with chronic liver disease: a populationbased study. Gut 2010; 59: 1410-1415 
Table 1: Frequency of AIH among different diabetes subtypes

\begin{tabular}{|c|c|c|c|c|}
\hline \multirow{2}{*}{$\begin{array}{c}\text { Type of } \\
\text { diabetes }\end{array}$} & Total No. & \multicolumn{3}{|c|}{ Patients with AIH (n/\%) } \\
& & & & \\
& & $<\mathbf{1 8}$ yrs. & yrs. & Total \\
\cline { 3 - 5 } & & & $21(0.04)$ & $50(0.04)$ \\
\hline Type 1 diabetes & 111,547 & $29(0.05)$ & $73(0.02)$ & $74(0.02)$ \\
\hline Type 2 diabetes & 313,916 & $1(0.08)$ & $10(0.10)$ & $15(0.12)$ \\
\hline Type 3 diabetes & 12,404 & $5(0.23)$ & $104(0.03)$ & $139(0.03)$ \\
\hline Total & 437,867 & $35(0.06)$ & & \\
\hline
\end{tabular}

AIH: autoimmune hepatitis. The total frequency of AIH among different types of diabetes was statistically significant $(\mathrm{p}<0.001)$. 
Table 2: Patients with T3DM and autoimmune hepatitis

\begin{tabular}{|l|c|}
\hline \multicolumn{1}{|c|}{ Diagnosis } & Patients \\
\hline Mutation in the insulin-receptor gene & 1 \\
\hline Berardinelli-Seip syndrome & 1 \\
\hline Uncommon forms of immune-mediated & 15 \\
diabetes & 7 \\
\hline Diabetes caused by corticosteroids & 2 \\
\hline Diabetes after transplantation/malignancy & \\
\hline
\end{tabular}

(Multiple entries possible) 
Table 3: Demographical, clinical, and metabolic comparison of patients with T1DM with or without AIH.

\begin{tabular}{|c|c|c|c|}
\hline \multirow[t]{2}{*}{ Parameter } & \multicolumn{2}{|c|}{ T1DM } & \multirow[t]{2}{*}{ p-value } \\
\hline & No AIH & AIH & \\
\hline No. of patients & 111,497 & 50 & \\
\hline Age [years] & $\begin{array}{c}17.73 \\
(14.33- \\
36.74)\end{array}$ & $\begin{array}{c}17.26 \\
(13.73- \\
44.75)\end{array}$ & 0.92 \\
\hline$<18$ years & $53 \%$ & $58 \%$ & 0.75 \\
\hline Male patients & $53 \%$ & $40 \%$ & 0.25 \\
\hline Duration of diabetes [years] & $\begin{array}{c}6.96 \\
(2.76-13.49)\end{array}$ & $\begin{array}{c}8.04 \\
(3.32-13.61)\end{array}$ & 0.80 \\
\hline BMI $\left[\mathrm{kg} / \mathrm{m}^{2}\right]$ & $23.09 \pm 0.01$ & $22.84 \pm 0.66$ & 0.71 \\
\hline BMI-SDS & $0.107 \pm 0.003$ & $0.062 \pm 0.150$ & 0.77 \\
\hline HbA1c [mmol/mol] & $67.03 \pm 0.07$ & $64.86 \pm 3.16$ & 0.49 \\
\hline Insulin dose [units/kg] ${ }^{1}$ & $0.79 \pm 0.00$ & $1.06 \pm 0.05$ & $<0.001$ \\
\hline Aspartate Transaminase [U/I] & $25.59 \pm 0.14$ & $143.88 \pm 6.04$ & $<0.001$ \\
\hline Alanine Transaminase [U/I] & $22.86 \pm 0.14$ & $98.45 \pm 6.30$ & $<0.001$ \\
\hline Gamma-Glutamyltransferase [U/I] & $25.37 \pm 0.26$ & $203.11 \pm 10.81$ & $<0.001$ \\
\hline Conventional insulin therapy, \% & $13 \%$ & $11 \%$ & 0.62 \\
\hline Intensive insulin treatment, $\%$ & $59 \%$ & $58 \%$ & 0.86 \\
\hline Insulin pump therapy, \% & $28 \%$ & $31 \%$ & 0.70 \\
\hline Additional OAD therapy, \% & $2 \%$ & $3 \%$ & 0.90 \\
\hline Islet Cell Antibodies, \% & $60 \%$ & $25 \%$ & 0.07 \\
\hline
\end{tabular}




\begin{tabular}{|l|c|c|c|}
\hline Insulin Autoantibodies, \% & $67 \%$ & $49 \%$ & 0.34 \\
\hline Glutamic Acid Decarboxylase, \% & $59 \%$ & $66 \%$ & 0.69 \\
\hline Protein Tyrosine Phosphatase, \% & $52 \%$ & $14 \%$ & 0.08 \\
\hline Coeliac disease, \% & $2 \%$ & $3 \%$ & 0.45 \\
\hline Thyroid disease, \% & $10 \%$ & $36 \%$ & $<0.001$ \\
\hline
\end{tabular}

T1DM: type 1 diabetes mellitus; T2DM: type 2 diabetes mellitus; AIH: autoimmune hepatitis Except for age, sex and duration of diabetes, values are adjusted means \pm SEM. Adjustments were made for age, sex, and diabetes duration. T1DM: type 1 diabetes mellitus; AIH: autoimmune hepatitis; BMI: body-mass-index; OAD: oral antidiabetic drugs. 
Table 4: Demographical, clinical, and metabolic comparison of patients with T2DM with or without AIH.

\begin{tabular}{|c|c|c|c|}
\hline \multirow[t]{2}{*}{ Parameter } & \multicolumn{2}{|c|}{ T2DM } & \multirow[t]{2}{*}{ p-value } \\
\hline & No AIH & AIH & \\
\hline No. of patients & 313,842 & 74 & \\
\hline Age [years] & $\begin{array}{c}70.07 \text { (60.32- } \\
77.67)\end{array}$ & $\begin{array}{c}67.06(57.73- \\
74.40)\end{array}$ & 0.05 \\
\hline$<18$ years & $1 \%$ & $0.4 \%$ & 0.26 \\
\hline Male patients & $52 \%$ & $18 \%$ & $<0.001$ \\
\hline Duration of diabetes [years] & $\begin{array}{c}8.22 \\
(2.79-14.82)\end{array}$ & $\begin{array}{c}5.93 \\
(1.23-9.78)\end{array}$ & 0.007 \\
\hline BMI $\left[\mathrm{kg} / \mathrm{m}^{2}\right]$ & $30.70 \pm 0.01$ & $30.46 \pm 0.76$ & 0.75 \\
\hline $\mathrm{HbA1c}[\mathrm{mmol} / \mathrm{mol}]$ & $59.51 \pm 0.04$ & $62.31 \pm 2.61$ & 0.28 \\
\hline Insulin dose [units/kg] ${ }^{1}$ & $0.59 \pm 0.00$ & $0.74 \pm 0.06$ & 0.03 \\
\hline Aspartate Transaminase [U/I] & $32.88 \pm 0.17$ & $72.26 . \pm 6.94$ & $<0.001$ \\
\hline Alanine Transaminase [U/I] & $33.55 \pm 0.16$ & $90.57 \pm 6.80$ & $<0.001$ \\
\hline Gamma-Glutamyltransferase [U/I] & $72.42 \pm 0.40$ & $231.96 \pm 17.78$ & $<0.001$ \\
\hline Insulin only, $\%$ & $28 \%$ & $53 \%$ & $<0.001$ \\
\hline Insulin plus OAD, \% & $20 \%$ & $13 \%$ & 0.15 \\
\hline OAD only, $\%$ & $25 \%$ & $13 \%$ & 0.01 \\
\hline Lifestyle modification, \% & $27 \%$ & $21 \%$ & 0.67 \\
\hline Coeliac disease, $\%$ & $0.2 \%$ & $1.4 \%$ & 0.05 \\
\hline Thyroid disease, $\%$ & $5 \%$ & $21 \%$ & $<0.001$ \\
\hline
\end{tabular}

Except for age, sex and diabetes duration, values are adjusted means \pm SEM. Adjustments were made for age, sex and diabetes duration. T2DM: type 2 diabetes mellitus; AIH: autoimmune hepatitis; BMI: body-mass-index; OAD: oral antidiabetic drugs, ${ }^{1}$ for patients with insulin therapy. 